\title{
The numerical analysis of the long-term behaviour of the reinforced concrete beams strengthened with carbon fibre reinforced polymer: Cracking
}

\author{
Mykolas Daugevičius ${ }^{1}$, Juozas Valivonis ${ }^{2}$, Tomas Skuturna ${ }^{3}$ \\ Department of Reinforced Concrete Structures and Geotechnics, \\ Vilnius Gediminas Technical University, Vilnius, Lithuania \\ E-mail: 'mykolas.daugevicius@vgtu.lt (correspondingauthor)
}

\begin{abstract}
The paper presents the analysis of the long-term deformability of the reinforced concrete beams strengthened with CFRP. The analysis is based on the obtained numerical and experimental data. The development of deformations is divided into stages. The comparison of the cracking process in the compressed and tensioned areas is performed. The comparative analysis of the results has shown that more attention should be paid to the creep of concrete and the influence of the tensioned reinforcement when the external load is decreased. The study has shown that the compression of the section subjected to long-term loading turns into tension when the external load is removed. Due to the effect of the tensile force, cracks appear on the top of the compressed section. Therefore, re-loading of the beam requires further evaluation of the strength degradation in the concrete of the compressed area.
\end{abstract}

Keywords: numerical analysis, long-term loading, cracking.

\section{Introduction}

Most of the experimental research works dealing with reinforced concrete consider the condition of the short-term loading. In this case, the influence of creep and shrinkage on the behaviour of the beams is negligible. Only the cracking moment can slightly decrease due to shrinkage. The creep of concrete causes redistribution of the internal forces between concrete and reinforcement. The developed creep strains decrease concrete ductility. Meanwhile, the external load magnitude can change in the service period. For example, the load on the bridges can increase and decrease depending on the intensity of transport. The load on the building can change when its purpose is changed. When the purpose of the building is changed and the external load is removed, while a new load is added, the structural element experiences a stage of unloading and loading. After unloading, the plastic (creep) strain in concrete remains, and when the load is added again concrete works with new mechanical properties. The purpose of the paper is to demonstrate the behaviour of the reinforced concrete beams which were loaded with a long-term load, then unloaded and loaded till failure. For this purpose, the numerical analysis of beams reported in the previous works (Daugevičius, Valivonis, \& Marčiukaitis, 2012; Daugevičius \& Valivonis, 2013) was performed.

\section{The experimental and numerical data}

In the earlier published manuscript (Daugevičius $\mid \&$ Valivonis, 2013), the developed cracks were divided into two groups. When the bending test was performed, the facade of the beam was divided into two zones and the appeared cracks were assigned for these zones. The first zone is the bending zone, where only the bending moment acts, while the second zone is the area where the shear forces and moments act. The evolution of the vertical cracks in the bending zone until the long-term load is reached is the same in the considered beams. However, the evolution character changes during the long-term period. In fact, the development of vertical cracks in the period of long-term loading in the beams B11S and B12S has stopped. However, the development of the vertical cracks in the beams B3S and B4S has not stopped. This difference in the character of evolution is closely related to the variation in the depth of the neutral axis. Figure 1 shows the distribution of cracks at all loading stages. White cracks represent the evolution of cracks observed until the long-term load level is reached. Green colour shows the evolution of cracks during the long-term loading period. Red colour represents the evolution of cracks in the period until the ultimate load is reached. 
a)

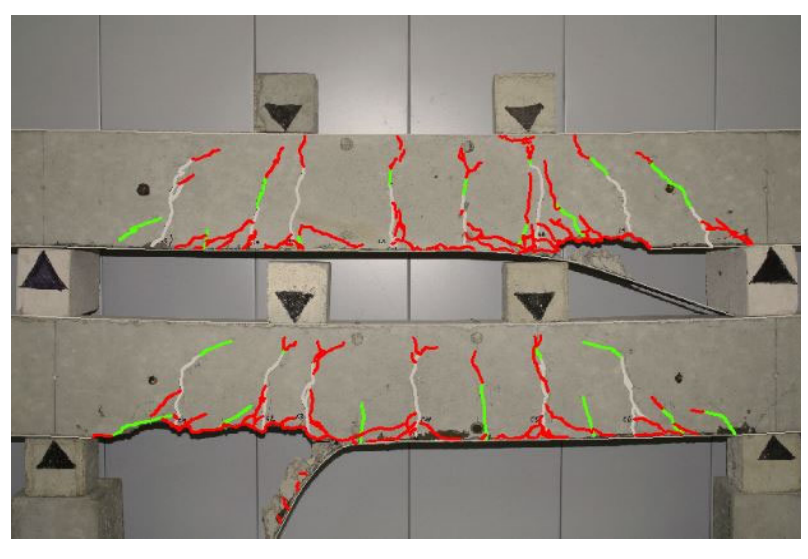

b)

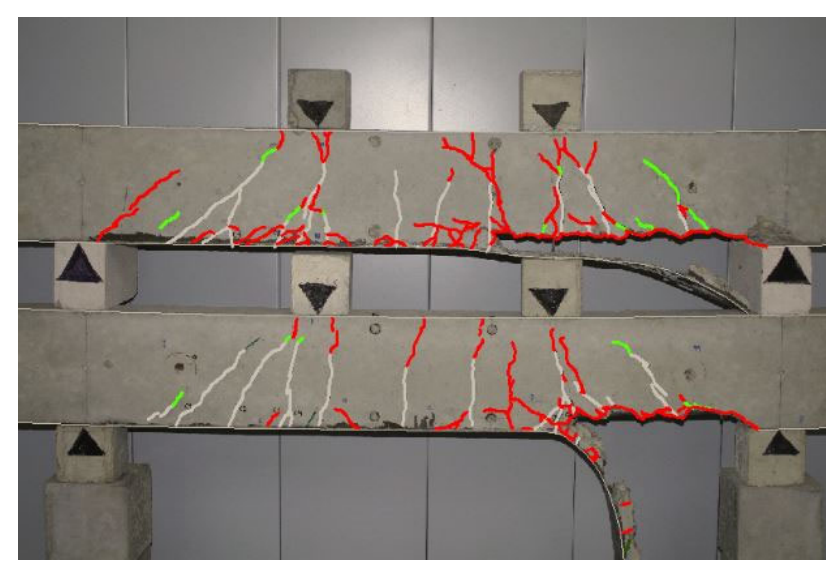

Figure 1. The evolution of cracks prior to the beam's failure (red colour): a is the cracking character of the beams B3S and B4S, b is the cracking character of the beams $\mathrm{B} 11 \mathrm{~S}$ and $\mathrm{B} 12 \mathrm{~S}$

The evolution of cracks in FEA beams is closely connected with the particular work stages. Work stages of the beams B3S and B4S are presented in Table 1. Work stages of the beams B11S and B12S are given in Table 2.

Table 1. Loading stages of the beams B3S and B4S

\begin{tabular}{|l|l|}
\hline $0 \ldots . . . . I_{\mathrm{a}}$ & \multicolumn{1}{|c|}{ The RC beam loaded until the long-term load level was reached } \\
\hline $\mathrm{II}_{\mathrm{a} . . . \mathrm{II}_{\mathrm{b}}}$ & Retention of the long-term load and the beam's strengthening \\
\hline $\mathrm{II}_{\mathrm{b} . . . \mathrm{II}_{\mathrm{c}}}$ & Retention of the long-term load after the beam's strengthening \\
\hline $\mathrm{II}_{\mathrm{c} . . . \mathrm{II}_{\mathrm{d}}}$ & The external load increased to achieve the new long-term load level \\
\hline $\mathrm{II}_{\mathrm{d} . . . \mathrm{I}_{\mathrm{e}}}$ & Retention of the long-term load \\
\hline $\mathrm{II}_{\mathrm{e} . . . . \mathrm{II}_{\mathrm{f}}}$ & Unloading \\
\hline $\mathrm{II}_{\mathrm{f} . . . \mathrm{II}_{\mathrm{g}}}$ & Retention of the unloaded beam \\
\hline $\mathrm{II}_{\mathrm{g} . . . . I_{h} . . . \mathrm{III}}$ & Loading until the beam's failure \\
\hline
\end{tabular}

Table 2. Loading stages of the beams B11S and B12S

\begin{tabular}{|c|l|}
\hline $0 \ldots . . . . I_{\mathrm{a}}$ & \multicolumn{1}{|c|}{ RC strengthened beam loaded until the long-term load level was reached } \\
\hline $\mathrm{II}_{\mathrm{a}} . . \mathrm{II}_{\mathrm{b}}$ & Retention of the long-term load \\
\hline $\mathrm{II}_{\mathrm{b} . . . \mathrm{II}_{\mathrm{c}}}$ & Unloading \\
\hline $\mathrm{II}_{\mathrm{c} . . . \mathrm{II}_{\mathrm{d}}}$ & Retention of the unloaded beam \\
\hline $\mathrm{II}_{\mathrm{d} . . . \mathrm{II}} . . . \mathrm{III}$ & Loading until the beam's failure \\
\hline
\end{tabular}

The numerically predicted evolution of cracks presented in Figures 2.1, 2.2, 3.1 and 3.2. Figures 2.1 and 2.2 present the evolution of cracks in the beams B3S and B4S for both FEA models. The most explicit evolution can be observed in the model with a denser mesh. Three and four normal cracks can be observed in the experimental beams and two cracks can be observed in the numerically analysed beams B3S and B4S (Figure 2.1, a). During the long-time loading period, two new cracks appeared in the unstrengthened beams B3S and B4S (Figure 2.1, b), while new cracks in the beams B11S and B12S had not appeared (Figure 3.1, b). Then, the level of the external load was increased, the height of the existing normal cracks increased and the new sources of cracks appeared (Figure 2.1, c). Later, during the period of long-term loading, normal cracks continued to develop (Figure 2.1, d). At this stage, new shear cracks could be observed around the supports. After unloading, tensile stresses developed in the top section (which was a compressed part) (Figure 2.1, e). In the period of retaining the beams without any external loads, the tensile stresses in the previously compressed part of the section arises (Figure 2.1, f). Later, when the beams were loaded until their failure, the tensile stresses in the previously compressed part of the section disappeared. Only new tensile stresses could be observed near the loading plates. The load was increasing even after the yielding of the tensile reinforcement was reached, and when large displacements were obtained the computation process was stopped. 
The cracks in the strengthened beams B11S and B12S distributed denser than the cracks in the ordinary beams B3S and B4S (Figure 3.1, a). In the period of the long-term load action, the tensile stresses concentrated about the loading plate in the beam with the smallest mesh. However, in the beams with larger meshes, no concentration near the loading plates could be observed, but major development of strains could be seen in the regions subjected to the action of the shear forces (Figure 3.1, b). As mentioned above, new normal cracks had not developed in the beams $\mathrm{B} 11 \mathrm{~S}$ and B12S. This could be related to the initial length between the normal cracks. After unloading, tensile stresses in the top section developed in a similar way as in the beams B3S and B4S (Figure 3.1, c). The distribution and the magnitude of tensile stresses increased after a particular time (Figure 3.2, d). The computation process was stopped after the high displacements were obtained in these beams.

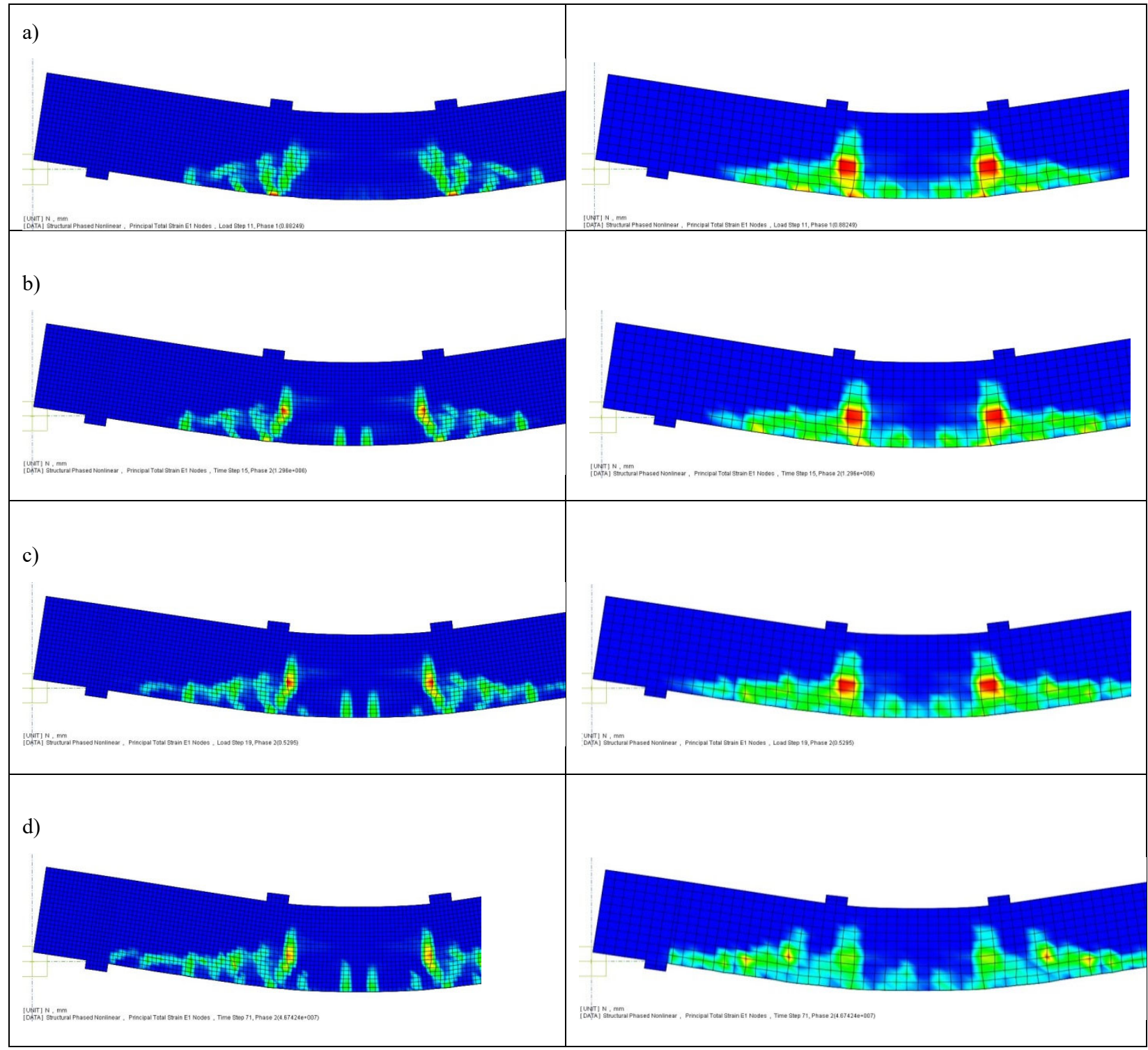

Figure 2.1. The evolution of the principal strain E1 at all service stages in the beams B3S and B4S: a) is the evolution of strains at stage $0 . \ldots \mathrm{I}_{\ldots} . . \mathrm{II}_{\mathrm{a}} ; \mathrm{b}$ ) denotes strains at stage $\mathrm{II}_{\mathrm{a}} \ldots \mathrm{II}_{\mathrm{b}} \ldots \mathrm{II}_{\mathrm{c}} ; \mathrm{c}$ ) shows the strains at stage $\mathrm{II}_{c} \ldots \mathrm{II}_{\mathrm{d}}$ and $\mathrm{d}$ ) denotes strains at stage $\mathrm{II}_{\mathrm{d}} \ldots \mathrm{II}_{\mathrm{e}}$ 


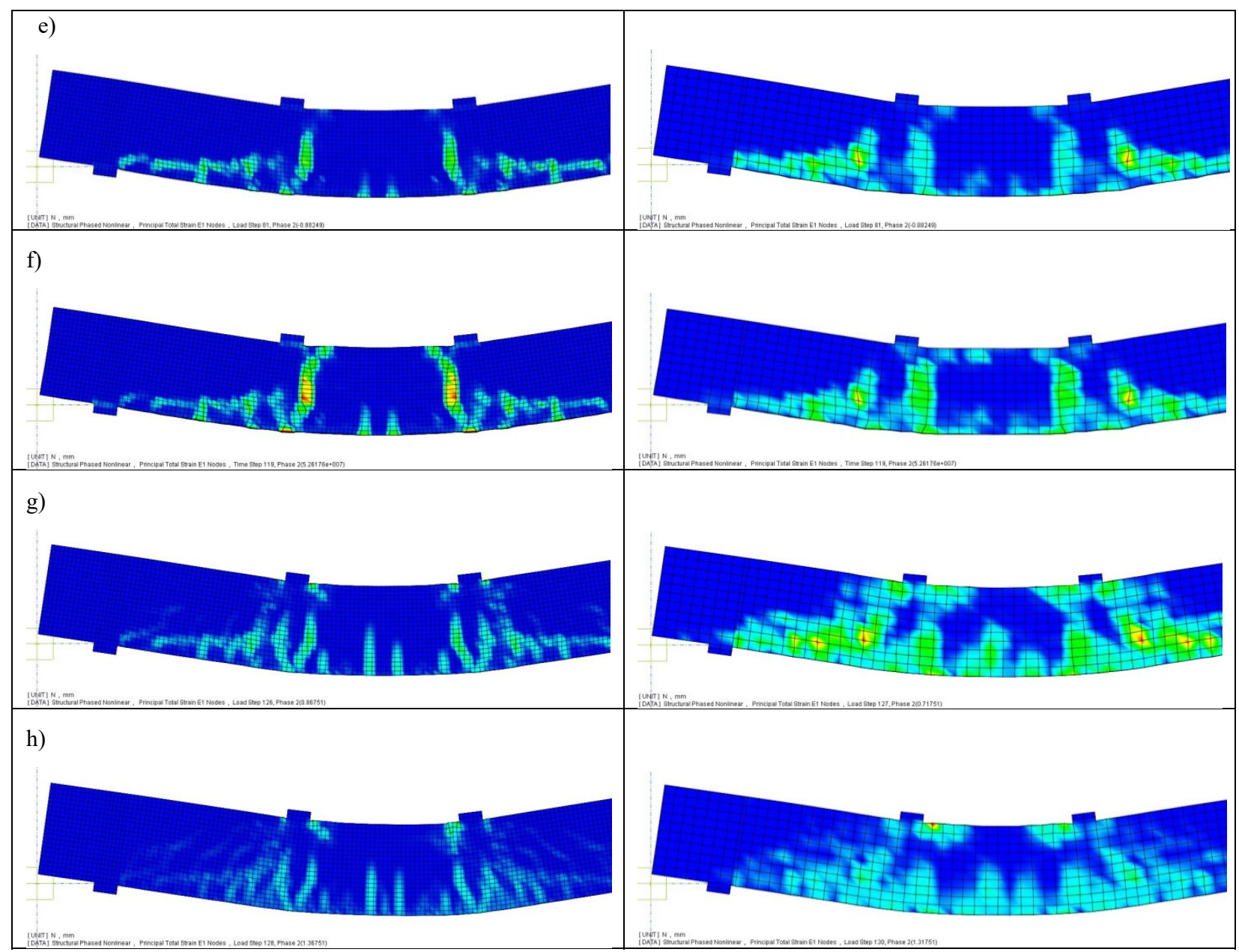

Figure 2.2. The evolution of the principal strain E1 at all service stages in the beams B3S and B4S: e) denotes strains at stage II...$I I f$, f shows strains at stage IIf...IIg, g denotes strains at stage IIg...IIh...III and $h$ shows strains at stage III (failure)

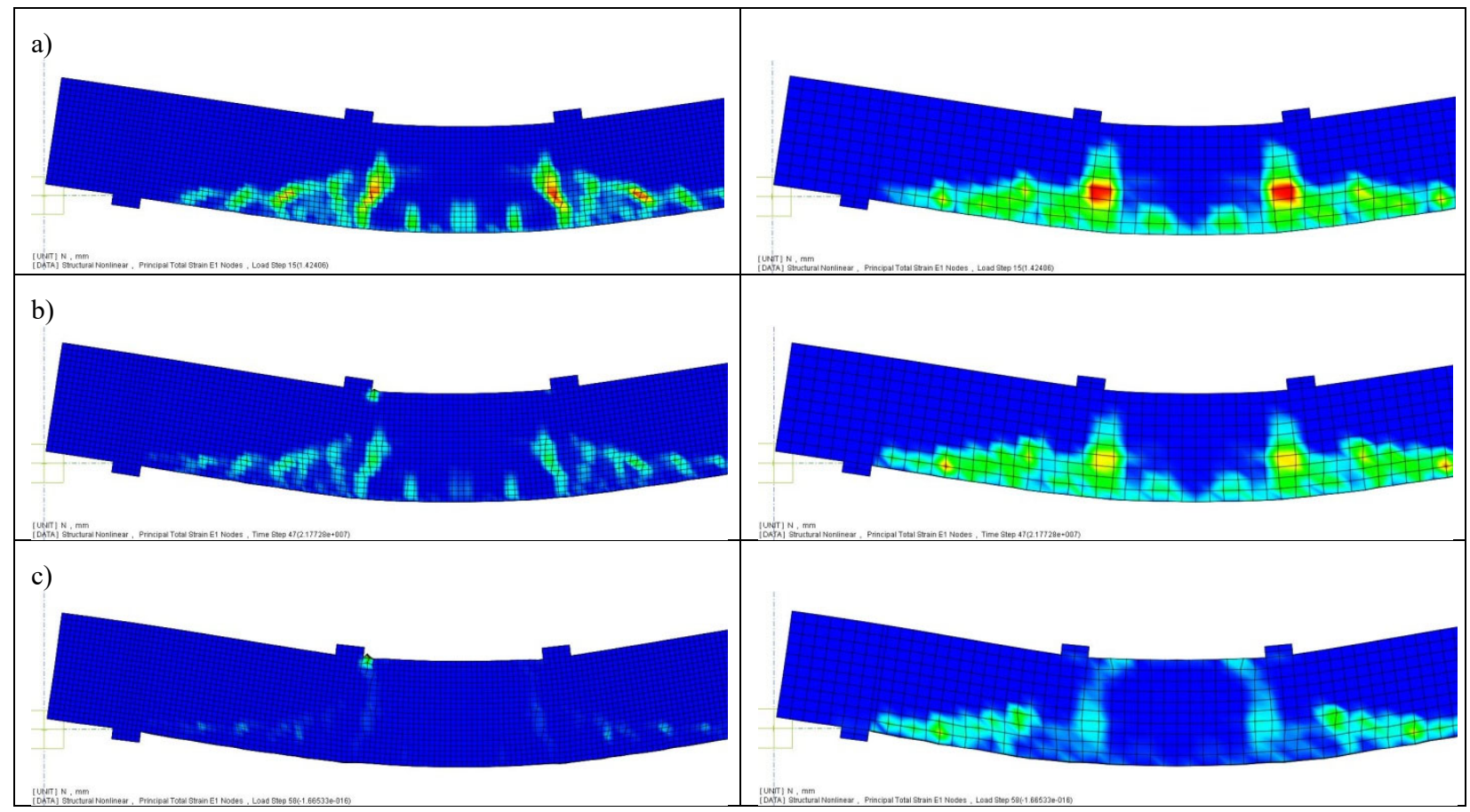

Figure 3.1. The evolution of the principal strain E1 in the beams B11S and B12S at all service stages: a is the evolution of strains at stage $0 . \ldots . . . . I_{a}, b$ shows strains at stage $\mathrm{II}_{\mathrm{a}} \ldots . . \mathrm{II}_{\mathrm{b}}$ and $\mathrm{c}$ denotes strains at stage $\mathrm{II}_{\mathrm{b} . . . \mathrm{II}_{\mathrm{c}}}$ 


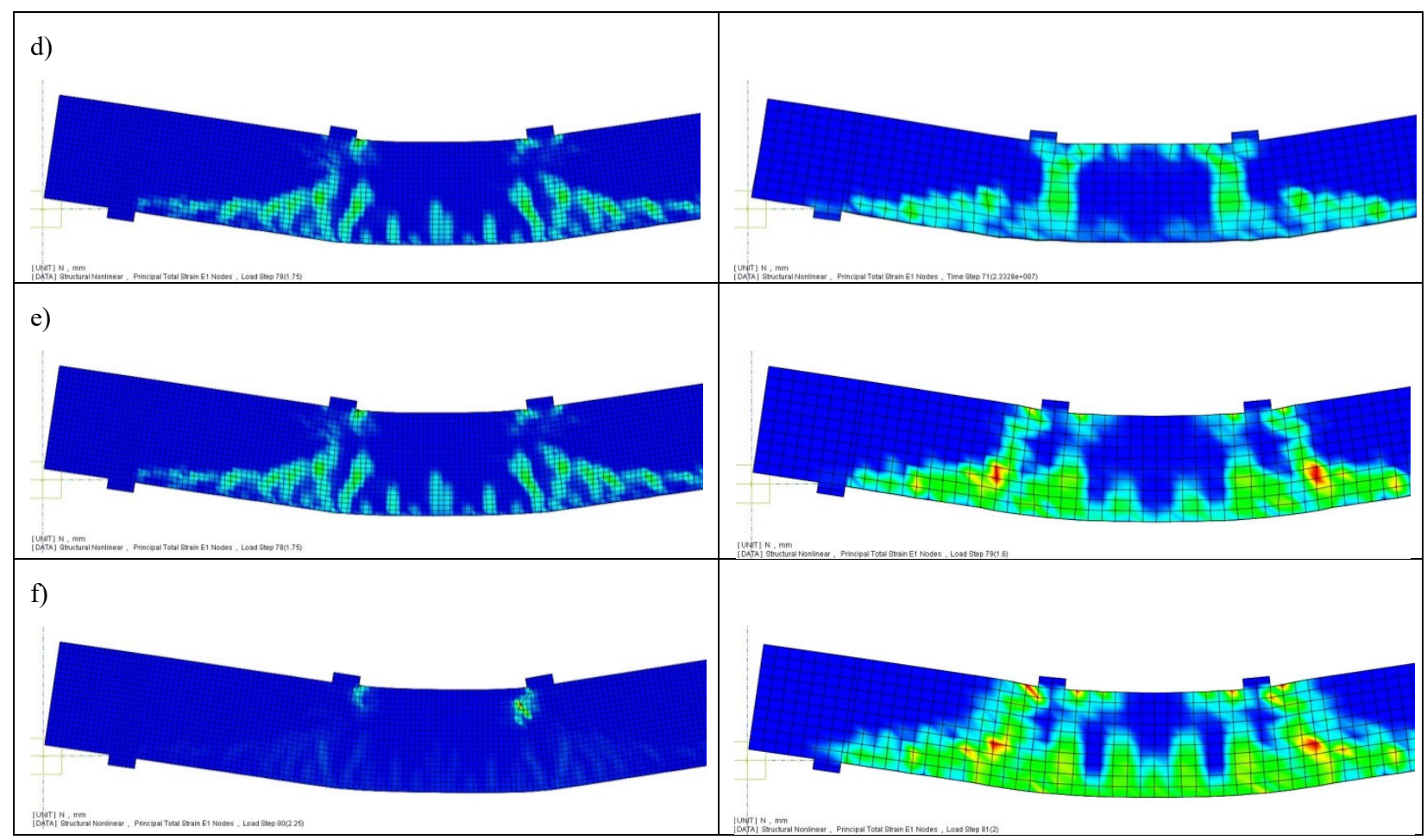

Figure 3.2. The evolution of the principal strain $\mathrm{E} 1$ in the beams B11S and B12S at all service stages: d) presents strains at stage

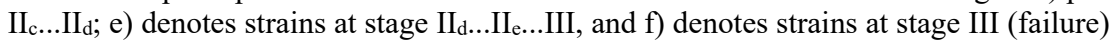

\section{Conclusions}

The development of tensile stresses in the cross-section previously subjected to compression requires more attention from designers. The propagation of micro cracks under the action of the tensile load changes the mechanical properties of concrete. The modulus of elasticity and the compressive strength of unaffected concrete will differ to some extent. This makes the evaluation of the structure's workability more complicated, and designers have to use some additional design tools, for example, nonlinear analysis software.

\section{References}

Daugevičius, M., \& Valivonis, J. (2013, June). Behavior of reinforced concrete beams strengthened with CFRP under long-term load action. In $11^{\text {th }}$ International Symposium on Fiber Reinforced Polymers for Reinforced Concrete Structures (FRPRCS11). Guimarães, Portugal.

Daugevičius, M., Valivonis, J., \& Marčiukaitis, G. (2012). Deflection analysis of reinforced concrete beams strengthened with carbon fibre reinforced polymer under long-term load action. Journal of Zhejiang University-SCIENCE A (Applied Physics \& Engineering), 13(8), 571-583. https://doi.org/10.1631/jzus.A1100317 